\title{
Comparison of Conventional and Molecular Methods in the Detection of Mycobacterium tuberculosis in Clinically Suspected Samples of Tuberculosis
}

\author{
Tejashree A. ${ }^{*}$, Chandana Mavinakere and Krishna Karthik M. \\ Department of Microbiology, JSSMC, JSSAHER, Mysore - 560 043, India.
}

\begin{abstract}
Impeded diagnosis in Tuberculosis may be a major cause of morbidity and mortality among particular group of patients, hence better methods are needed for the accurate detection of tuberculosis (TB) among both smear positive and smear negative cases. This study was aimed to compare conventional and molecular methods in detecting Mycobacterium tuberculosis among the clinically suspected cases of TB. A total of $\mathbf{1 0 0}$ clinically diagnosed TB patients were incorporated in this study. All the patients were either admitted or attending JSS Hospital, Mysore during the study period i.e., from January 2018- December 2018. Sputum, Gastric aspirate, Pleural fluid, Ascitic fluid, Pus discharge, CSF and Tissue samples were gathered for smear microscopy, culture (Lowenstein - Jensen medium) and PCR testing. The sensitivity of smear and PCR were compared to that of culture considering as gold standard. 50 of 100 patients were positive on smear microscopy. 51 specimens yielded the growth of Mycobacterium tuberculosis on Lowenstein-Jensen's medium and PCR detected the presence of MTB specific gene in 77 specimens. In clinical diagnosis of tuberculosis, molecular methods are probably a useful adjunct certainly in smear negative paucibacillary cases. Early diagnosis of TB is cornerstone for proper treatment and control of this deadly disease. Polymerase chain reaction testing is the most rapid and sensitive method for the diagnosis of tuberculosis while culture is specific but it takes 4 to 8 weeks to provide results and smear testing is the cheapest but least sensitive test.
\end{abstract}

Keywords: Mycobacterium tuberculosis, Tuberculosis, patients, PCR, Mysore.

*Correspondence: dr_tejashree@yahoo.co.in; +91 9945566375

(Received: 09 April 2019; accepted: 20 May 2019)

Citation: Tejashree A., Chandana Mavinakere and Krishna Karthik M., "Comparison of Conventional and Molecular Methods in the Detection of Mycobacterium tuberculosis in Clinically Suspected Samples of Tuberculosis", J Pure Appl Microbiol., 2019; 13(2): 1217-1222. doi: 10.22207/JPAM.13.2.62

C The Author(s) 2019. Open Access. This article is distributed under the terms of the Creative Commons Attribution 4.0 International License which permits unrestricted use, sharing, distribution, and reproduction in any medium, provided you give appropriate credit to the original author(s) and the source, provide a link to the Creative Commons license, and indicate if changes were made. 


\section{INTRODUCTION}

Tuberculosis (TB) is the major airborne infectious bacterial disease caused by Mycobacterium tuberculosis (MTB) remains a major worldwide health problem. In the SouthEast Asian region (SEAR), India is amongst the high tuberculosis burden countries in the South-East Asian region(SEAR) ${ }^{1}$. India alone harbours one fourth of the global burden of tuberculosis patients ${ }^{2}$. There has been an increase in notification of new tuberculosis cases from India leading to an increase in notified cases by $37 \%$ in 2016 in comparison to that in $2013^{3}$. $T B$ is a disease for which the use of vaccines has shown no efficacy, hence the best control mechanisms to reduce transmission rates are early diagnosis and early treatment. Diagnostic procedure of tuberculosis begins with a high clinical suspicion, and is reinforced through the use of different diagnostics ${ }^{4,5}$. In spite of the fact that acid fast bacilli (AFB) microscopy, and conventional Lowenstein Jensen (L-J) culture remain the keystone of the diagnosis of TB, these traditional bacteriological methods are either slow or their sensitivity is fairly low, mainly with clinical samples that contain less number of organisms ${ }^{6}$. This can influence treatment by either delaying it or giving inappropriate empiric therapy for TB to subjects without mycobacterial infections or with atypical mycobacteria ${ }^{7}$. Microscopic analysis of Ziehl-Neelsen (ZN) stained smear preparations and sputum culture are the gold standard method for diagnosing pulmonary tuberculosis (TB) in spite of many advances in laboratory diagnostic techniques. ${ }^{8}$. Although it has a low sensitivity, the $\mathrm{ZN}$ technique remains the principal tool for detecting pulmonary $\mathrm{TB}^{9}$. The sputum culture can delay diagnosis by 3-6 weeks and has a biosafety hazard ${ }^{10}$. Along, culture may give false-negative results in $10-20 \%$ of cases $^{11,12}$. Despite these shortcomings, ZN is often employed in lowincome countries because it is low-cost and easy to conduct and culture is not common due to a lack of laboratory facilities, materials and trained professionals. Therefore, new diagnostic methods have been developed with the goal of replacing direct testing and culture. The classic test would be one that has high sensitivity, provides quick results and is inexpensive. Molecular techniques, such as polymerase chain reaction (PCR), reduce the time necessary for detection and identification of $M$. tuberculosis. Various studies have been done to detect $M$. tuberculosis in respiratory and other clinical samples by amplifying different DNA sequences of $M$. tuberculosis by polymerase chain reaction (PCR) test with encouraging results ${ }^{13,14}$. These studies have mainly focused on IS6110 sequence of mycobacterial genome and partly on $38 \mathrm{kDa}$ protein antigen $\mathrm{b}(\mathrm{Pab})$, and $65 \mathrm{kDa}$ antigen encoding gene. The present study was carried out targeting the 225bp gene coding for IS6110 sequence which is specific for $M$. tuberculosis complex. The study was aimed to compare the results of PCR with those of conventional techniques such as smear microscopy and culture by LJ media.

\section{MATERIALS AND METHODS}

A sum of 100 samples received at the DMC, department of Microbiology, JSS Hospital, Mysore with clinical suspicion of tuberculosis were included in the study. Of which 12 samples were received from patients with suspected extrapulmonary tuberculosis and 88 from patients with suspected pulmonary tuberculosis. The samples collected were processed for smear examination, culture on Lowensten-Jensen's media and detection of MTB specific gene using PCR. The results of all different diagnostics were compared and analysed. The sensitivity of PCR test, smear microscopy was evaluated considering culture as gold standard.

\section{Processing of samples}

Sample handling and all laboratory procedures were conducted following safety regulations and standardized handling measure. Smears were made from the mucopurulent part of sputa and other appropriate methods depending on the nature of sample. Zeihl-Neelsen (ZN) staining was done on these smears using standard techniques and observed for the presence of acid fast bacilli (AFB). AFB was graded using IUALTD recommendations. All the specimens were further subjected to digestion and decontamination using standard N-acetyl L-cysteine - NaoH (NALC-NAOH) method. Sediments obtained after processing the samples were inoculated into two bottles of LJ-Medium. One bottle was incubated at room temperature and other at $37^{\circ} \mathrm{C}$. Culture readings were taken on weekly basis until eight weeks. The 
Mycobacterial isolates obtained were subjected to MPT64Ag ICT test for confirmation of isolates as MTBC.

\section{DNA Extraction and amplification}

Samples such as sputum, pus and tissue were priorly treated with NALC-NAOH. Tissue specimens were transferred into centrifugation tubes. Lysis buffer, Proteinase $\mathrm{K}$ was added and homogenized and the tubes are centrifuged at 6000rpm for 5 minutes and binding buffer is added and purification steps are followed. Sterile body fluids were directly added with proteinase $\mathrm{K}$ and purification steps were followed as per manufacturers protocol.

DNA extraction and amplification of $225 \mathrm{bp}$ of M.tuberculosis was done by using commercially available $\mathrm{HELINI}^{\mathrm{TM}}$ pure fast bacterial genomic DNA minispin prep kit and HELINI MTB PCR kit. The samples were processed as per the guidelines of the manufacturer of the kit to obtain DNA. A 225bp region of IS6110 gene coding for $M$. tuberculosis was choosen as primer target for DNA amplification. DNA amplification by PCR was performed with a total reaction volume of $20 \mu \mathrm{l}$ by using Biorad PCR systems. The amplification reaction contained, Red dye PCR Master mix, Endogenous primer mix, MTB Primer mix and purified DNA sample at a final volume of $20 \mu$ l. MTB positive template provided by the manufacturer was used as positive control and sterile water was used as negative control for the amplification. Amplification protocol was set according to protocol, initial denaturation at $95 \mathrm{c}$ for 5 minutes followed by denaturation at $95 \mathrm{c}$ for 30 seconds, Annealing at $58^{\circ}$ for 30 seconds, Extension at $72^{\circ}$ for 30 seconds. After final extension the samples were immediately kept at $-20^{\circ}$. PCR products were using $1 \%$ agarose gel in $0.5 \mathrm{X}$ TAE buffer containing

Table 1.

\begin{tabular}{|c|c|}
\hline $\begin{array}{l}\text { Smear positive } \\
(n=50)\end{array}$ & $\begin{array}{l}\text { Smear negative } \\
(n=50)\end{array}$ \\
\hline 49- Sputum & 39- Sputum \\
\hline \multirow{5}{*}{ 1-Pus discharge } & 5- Gastric aspirate \\
\hline & 3- Pleural fluid \\
\hline & 1-Tissue \\
\hline & 1-Ascitic fluid \\
\hline & $1-\mathrm{CSF}$ \\
\hline
\end{tabular}

ethidium bromide at $10 \mu \mathrm{g} / \mathrm{ml}$ concentration and the samples showing the presence of band at $225 \mathrm{bp}$ under gel doc were considered as positive for M. tuberculosis.

Statistical analysis such as sensitivity and diagnostic accuracy for various diagnostic tests was calculated in this study.

\section{RESULTS}

Of 100 samples included, 50 were smear positive and 50 were smear negative (Table 1). Among 100 patients, 59 (59\%) of the patients were males and 41 (41\%) were females. The mean age of subjects among males and females were 44.63 and 40.15 . Considering 19.28 as standard deviation for males and 22.32 for females, overall age of the total subjects was $42.79 \pm 20.59$.

A total of 100 samples were subjected to microscopy, culture on LJ medium and PCR. The sensitivity of each test is compared (Table 2).

Table 2. Sensitivity of different tests conducted

\begin{tabular}{lcccc}
\hline $\begin{array}{l}\text { Tests } \\
\text { performed }\end{array}$ & $\begin{array}{c}\text { No of } \\
\text { samples } \\
\text { tested }\end{array}$ & & Result & \multicolumn{2}{c}{$\begin{array}{c}\text { Sensiti- } \\
\text { vity }\end{array}$} \\
\cline { 3 - 4 } & & Positive & Negativen & \\
\hline ZN smear & 100 & 50 & 50 & $50 \%$ \\
PCR & 100 & 77 & 33 & $77 \%$ \\
Culture on & 100 & 51 & 49 & $51 \%$ \\
LJ-Media & & & & \\
\hline
\end{tabular}

Sensitivity of PCR test with two different tests was compared for pulmonary and extrapulmonary samples. The PCR test gave a higher sensitivity compared to ZN smear and LJ medium in both pulmonary and extra pulmonary samples (Table 3).

Table 3. Sensitivity of different tests in pulmonary and extra pulmonary samples

\begin{tabular}{lccc}
\hline & \multicolumn{3}{c}{$\begin{array}{l}\text { Identification rate in percentage, } \\
\text { (number) by different tests }\end{array}$} \\
\cline { 2 - 4 } $\begin{array}{l}\text { Nature of } \\
\text { Clinical }\end{array}$ & $\begin{array}{c}\text { ZN } \\
\text { Samples }\end{array}$ & $\begin{array}{c}\text { LJ } \\
\text { (Positive) }\end{array}$ & PCR \\
\hline Pulmonary & & & \\
Extrapulmonary & $\begin{array}{c}\text { 85.90(49) } \\
\text { 8.33(1) }\end{array}$ & $54.50(48)$ & $81.80(72)$ \\
& & & $41.60(5)$
\end{tabular}


The diagnostic accuracy of PCR was calculated by considering culture as gold standard and the diagnostic accuracy of PCR is $74 \%$ (Table 4).

Table 4. Diagnostic accuracy of PCR v/s culture

\begin{tabular}{lcccc}
\hline & \multicolumn{2}{c}{ Culture } & Total \\
\cline { 3 - 4 } & & Positive & Negative & \\
\hline \multirow{2}{*}{ PCR } & Positive & 17 & 10 & 37 \\
& Negative & 0 & 23 & 23 \\
\multirow{2}{*}{ Total } & & 17 & 33 & 50 \\
\hline
\end{tabular}

\section{DISCUSSION}

World health organization on the motto of end TB strategy and with the goal of reducing the spread of TB has been recommending for the development of newer and reliable TB diagnostic tools which would be more sensitive and simpler ${ }^{15,16}$. Scientists and researchers around the world have been working on these strategies of ending TB and reducing the spread of infection. Efforts for development of rapid and low cost tests with high sensitivity and specificity which can be used in limited resource settings as a point of care diagnostics are still on its way with the goal of decreasing TB. Evidence based diagnosis like smear microscopy is very much needed for the efficient diagnosis of TB. But it has its own limitations such as low sensitivity ${ }^{17}$. Hence, this is the primary disadvantage and there is a need for developing new tools to diagnose tuberculosis ${ }^{18}$. Sensitivity of Microscopy in our study is $50 \%$, was moderately high than compared to other studies. This might be due to in appropriate selection of samples where among a total of 100 samples, 50 smear positive and 50 smear negative samples. A wide range of smear positivity between $0-75 \%$ has been reported in earlier studies ${ }^{19}$. Prompt and accurate diagnosis of tuberculosis is still a dilemma in developing countries where LJ culture is still used as the gold standard for its diagnosis. The culture is time consuming (4-8 weeks) therefore, evidences like histology/cytology along with clinical evaluation are still being used to treat the patient with a full course of anti-tubercular treatment ${ }^{20}$. In the present study, the sensitivity and yield of culture positivity was almost equivalent when compared with the smear positivity. Our study showed sensitivity of $51 \%$ which has varied results when compared with the studies by Dunlap et al. and Yeager et al. They showed a culture sensitivity of $80-85 \%^{21,22}$. The higher sensitivity towards culture is because, detection of Mycobacterium tuberculosis using culture on LJ medium is very specific and can detect as few as 10 bacteria/ $\mathrm{ml}$ of specimen as compared to smear that requires about 5000 to 10000 acid-fast bacilli / $\mathrm{ml}$ of specimen. Diagnostic techniques based on amplification have the potential to increase the sensitivity for detecting mycobacterium which can also reduce the turnaround time that is usually necessary to isolate and to identify these organisms using biochemical reactions $s^{23,24}$. A sensitivity of $77 \%$ for PCR test was seen in our study, this is concordance with a study who reported a sensitivity of $74.4 \%{ }^{25}$. Various studies showed varied results for sensitivity for PCR. In a study conducted by Muhammad Kashif Munir et al., sensitivity of $92 \%$ was reported. The sensitivity of PCR was remarkably high when compared to smear and culture in this study and PCR took much shorter time (1-3 days) as compared to culture (6-8 weeks). In a pooled analysis of 125 studies $^{26}$, the overall sensitivity of PCR was $85 \%$. The results of this study states that smear is cheap and rapid method of detecting mycobacterium tuberculosis but it has a very low sensitivity. Culture is more sensitive but it takes a longer time to give results while PCR is specific, rapid, more sensitive but expensive technique, and can be used in difficult cases where diagnosis become a challenge.

\section{CONCLUSION}

The rate of infection with Tuberculosis, it's mortality and morbidity rates are in the line of increasing in recent years, hence, rapid and accurate diagnosis and treatment plays an important role in reducing the risk of increasing the rates of infection including the morbidity and mortality. Staining techniques such as ZN and Auramine staining for acid fast bacilli is fast and inexpensive but has its own limitation of less sensitivity and also cannot differentiate between typical and atypical Mycobacteria. Diagnosis by culture, even though being gold standard, relatively specific and sensitive in comparison with smear microscopy but slow and time taking process. A quicker and yet accurate diagnosis 
of Mycobacterium tuberculosis is pivotal in the management of TB. PCR is specific, rapid, more sensitive but expensive technique. The sensitivity of PCR was remarkably high when compared to smear and culture in this study i.e., out of 100 test samples 77 were positive for PCR, 51 were positive for culture and 50 were smear positive and PCR took much shorter time (1-3 days) as compared to culture (6-8 weeks). Hence, from our study we conclude that for timely detection and management of tuberculosis PCR can be used, which can help the physicians for timely decisions for patient's management. PCR can also be used in smear negative cases where diagnosis becomes a challenge.

\section{ACKNOWLEDGMENTS}

None.

\section{CONFLICT OF INTEREST}

conflict of interest.

The authors declares that there is no

\section{AUTHORS' CONTRIBUTION}

All authors have made substantial, direct and intellectual contribution to the work and approved it for publication.

\section{FUNDING}

None.

\section{DATA AVAILABILITY}

All datasets generated or analyzed during this study are included in the manuscript.

\section{ETHICS STATEMENT}

This article does not contain any studies with human participants or animals performed by any of the authors.

\section{REFERENCES}

1. World Health Organization. Bending the cur veending TB: Annual report 2017. India: World Health Organization, Regional office for South-East Asia;2017. Licence: CC BY-NC-SA 3.0 IGO. Geneva: World Health Organization; 2017. Available at: http://www.who.int/ iris/handle/10665/254762.

2. TB India 2017. Revised National Tuberculosis Control Programme. Annual status report. New Delhi: Central TB Division, Directorate General of Health Services; 2017. Available at: http://tbcindia.gov.in/ WriteReadData/TB\%20India \%202017.pdf.
3. World Health Organization. Global Tuberculosis Report 2017. WHO/HTM/TB/2017.23. Geneva: World Health Organization; 2017. Available at: http://www.who.int/ tb/publications/global_report/en /.

4. Foulds J., and O'Brien J. New tools for the diagnosis of tuberculosis, the perspective of developing countries. Int J Tuberc Lung Dis 1998; 2: 778-783.

5. Kar A., Modi-Parekh K., and Chakroborty A.K. Advances in tuberculosis diagnostics. Health Administrator, 2003; 15: 118-123.

6. Jonas V., Alden M.J., Curry J.I., Kamisango K., Knott C.A., Lankford R., Wolfe J.M., Moore D.F. Detection and identification of Mycobacterium tuberculosis directly from sputum sediments by amplification of rRNA. J. Clin. Microbio., 1993; 31: 2410-2416.

7. Noel A.B., Lecossier D., Nassif X., Birgite Gicquel, Frebault V.L., Hance A.J. Rapid diagnosis of tuberculosis by amplification of Mycobacterial DNA in clinical samples. Lancet, 1989; 2(8671): 1069-1071.

8. Brasil. Ministe' rio da Sau' de. Programanacional de controled a tuberculose. Manual de Recomendac, o es para o Controle da Tuberculose no Brasil. 1st edn. Bras|lia: Secretaria de Vigila^ nciaemSau’ de; 2011.

9. World Health Organization. WHO global report 2011. http://www.who.int/tb/laboratory/en. Accessed October 31, 2013.

10. World Health Organization. Systematic screening for activetuberculosis. Principles and recommen-dations. http:// www.who.int/tb/tbscreening/en. Accessed November 1, 2013.

11. Dye C., Scheele S., Dolin P., Pathania V., Raviglione M.C. Consensus statement. Global burden of tuberculosis: estimated incidence, prevalence, and mortality by country. WHO Global Surveillance and Monitoring Project. JAMA, 1999; 282: 677-686, doi: 10.1001/ jama.282.7.677.

12. Pai M., Flores L.L., Hubbard A., Riley L.W., Colford J.M. Jr. Nucleic acid amplification tests in the diagnosis of tuberculouspleuritis: a systematic review and meta-analysis. BMC Infect. Dis., 2004; 4: 6, doi: 10.1186/1471-2334-4-6.

13. Montenegro S.H., Gilman R.H., Sheen P., Cama R., Cavides L., Hopper T., Chambers R., Oberhelman R.A. Improved detection of $M$. tuberculosis in Peruvian children by use of heminested IS6110 PCR assay. Clin. Infec. Dis., 2003; 36: 16-23.

14. Bennedsen J., Thomsen V.O., Pfyffer G.E., Funke G., Feldmann K., Beneke A., Jenkins P.A., Hegginbotham M., Fahr A., Henystler M., Cleator G., Klapper P., Wilkin E.G.L. Utility of PCR in diagnosing pulmonary tuberculosis. J. Clin. Microb., 1996; 34:1407-1411.

15. WHO. The global plan to stop TB 2011-2015. Geneva: World Health Organization; 2010.

16. Updated guidelines for the use of nucleic acid amplification tests in the diagnosis of tuberculosis. MMWR Morb. Mortal. Wkly. Rep., 2009; 58: 7-10.

17. Baily G.V.J., Savic D., Gothi G.D., Naidu V.B., Nair S.S. Potential yield of pulmonary tuberculosis cases by direct microscopy of sputum in a district of South India. Bull. World Health Organ, 1967; 37(6): 875-892

18. Foulds J., and O'Brien J. New tools for the diagnosis of tuberculosis, the perspective of developing countries. 
Int J Tuberc Lung Dis 1998; 2: 778-783.

19. Kamboj S.S., Goel M.M., Tandon P.I. Correlation study of histopathology and bacteriology in patients of tubercular lymphadenitis. Indian J. Chest Dis. Allied Sci., 1994; 36: 187-91.

20. World Health Organization. Treatment of tuberculosis: guidelines for national programmes. [Geneva]: WHO; 1993.

21. Dunlap N.E., Bass J., Fujiwara P. Diagnostic standards and classification of tuberculosis in adults and children. Am. J. Respir. Crit. Care. Med., 2000; 161: 1376-95.

22. Yeager I.I.J. Jr, Lacy J., Smith L. Quantitative studies of mycobacterial populations in sputum and saliva. Am. Rev. Respire Dis., 1967; 95: 998-1004.

23. Horner P.J., Moss F.M.: Tuberculosis in HIV infection.
Int. J. STD AIDS, 1991; 2: 162-7.

24. Selwyn PA: Tuberculosis in the AIDS era: A new threat from an old disease. State J. Med., 1991, 91: 233-35.

25. Negi S.S., Khan S.F.B., Gupta S., Pasha S.T., Kare S., Lal S. Comparison of the conventional diagnostic modalities, BACTEC culture and polymerase chain reaction test for diagnosis of tuberculosis. Indian J. Med. Microbiol., 2005; 23: 29-33.

26. Ling D.I., Flores L.L., Riley L.W., Pai M. Commercial nucleic-acid amplification tests for diagnosis of pulmonary tuberculosis in respiratory specimens: meta-analysis and meta-regression. PLOS ONE, 2008; 2: e1536 Available from: URL:www.plosone.org. 